\title{
'THE EFFECT OF THE TUBERCULO-TOXIN ON THE ADRENAL FUNCTION *
}

\author{
L. H. NEWBURGH, Bostox axd T. H. KELLY, Cincixxati
}

The following work was undertaken for the purpose of producing an experimental chronic insufficiency of the adrenal glands. It was then our intention to study this experimental insufficiency in relation to the other glands of internal secretion, and to compare it with the clinical picture of Addison's disease.

Thus far all experimental work has resulted only in an acute insufficiency of the adrenal function. Excision of the glands is followed by death in two or three days. It was accordingly necessary to devise some means of slowly but progressively injuring the function of the glands. For this purpose it was decided to try the injection of tuberculin over long periods. Tuberculin was selected because of the evidence presented by certain workers in this field that chronic tuberculosis causes a sclerosis and atrophy of the adrenal glands.

Bernard and Bigard ${ }^{1}$ have found, in the adrenals of the tuberculous, a sclerosis beginning at the ressels, causing lobulation of the glands, especially manifest in the cortex, but also invading the medulla. This can go on to complete atrophy in cases of intense sclerosis. Parisot and Lucien $^{2}$ have shown that the extracts of the adrenals of persons dying of chronic tuberculosis have a less intense hypertensive action than those of normal extracts. Boinet ${ }^{3}$ states that cases of adrenal sclerosis are more numerous than primary tuberculosis or cancer of the adrenals; and that this condition, with or without melanodermie, is common in the course of, or at the end of, pulmonary tuberculosis. The above mentioned workers believe that the anatomical and physiological changes noted by them resulted from the action of the tuberculo-toxin.

*Fron the Joseph Eichberg Laboratory of Physiology, University of Cincinnati.

1. Bernard, L., and Bigard: Les processus sécrétoires dans la substance corticale de la glande surrénale. Compt rend. Soc. de biol., 1905, lix. 504 (quoted by Boinet).

2. Pariset, J., and Lucien, M.: Etude physiologique et anatomique des capsules surrénale chez les tuberculeux. Reunion biologique de Nancy, 1907, lxiii, 525 (quoted by Boinet).

3. Boinet, E.: Opotherapie Surrénale dans la maladie d'Addison. Bull. de l'Acad. de Med., Paris, 1909, series 3, lxii, 154. 
It seemed reasonable to assume that Koch's old tuberculin ${ }^{4}$ contained these toxins; and that if the changes described by Bernard and Bigard, Parisot and Lucien, and Boinet, were caused by products resulting from the growth of the tubercle bacillus in the human body, we might expect to produce similar effects by injecting tuberculin into rabbits. It was thought better to use tuberculin ${ }^{5}$ rather than to inoculate the animals with living bacilli because in the former case we could regulate the dose and because we could be sure there were no tubercle bacilli in the adrenal glands.

Our experimental procedure was as follows: We employed two series of animals. In the first series we started with very small doses of tuberculin in order not to kill the rabbits should they develop the signs of a toxemia. The first injections were $0.01 \mathrm{gm}$. repeated daily. No evidence of disease being noted, we gradually increased the dose up to $0.10 \mathrm{gm}$. In the second series the dose throughout was $0.10 \mathrm{gm}$. In no case did the animals show any of the symptoms of a toxemia. They did not lose weight or strength, remained lively and ate well. In several instances they gained weight.

The two functions of the adrenal secretion which are most firmly established, are the glycogenic and the pressor. It has been shown by Porges ${ }^{6}$ and others that persons suffering from Addison's disease, and dogs from whom the adrenals have been excised, have an amount of glucose in the blood far below the normal. Subcutaneous injections of adrenalin, on the other hand, cause a transient hyperglycemia. A low blood-pressure occurs in the great majority, and perhaps in all cases of true Addison's disease. Injections of minute doses of adrenalin, on the other haind, cause a sharp rise in blood-pressure.

In order to find whether we had interfered with or destroyed the functions of the adrenal glands in our animals we in the first place compared the percentage of glucose present in the arterial blood of rabbits which

4. Koch's old tuberculin (H. K. Mulford \& Co.) is prepared as follows: Tubercle bacilli are grown on glycerated broth for from thirty to sixty days. The culture is then poured into flat dishes and evaporated to one-tenth its original bulk over live steam. The filtrate from this concentrated broth is the finished product.

5. Concentrated old tuberculin was mixed with a sufficient amount of 0.9 per cent. salt solution to give the desired dilution. One c.c. of this solution was received into each of a series of ampoules; the latter were sealed and submerged in water; the water was boiled for five minutes. It was found necessary in the absence of a preserving fluid to take these precautions in order to maintain sterility.

6. Porges, O.: Zur Pathologie des Morbus Addison. Ztschr. f. klin. Med., Berl., $1910, \mathrm{Jxx}, 243$. 
had received injections of tuberculin over a long period of time with that found in normal rabbits. ${ }^{7}$

A striking decrease in the glucose content of the blood was found. In Rabbit XXIII, after $4.55 \mathrm{gm}$. of tuberculin had been given in the course of four months; and in Rabbit XXXV, after $\% .1 \mathrm{gm}$. had been given in the course of three months, the glucose was present in such minute amounts that no test with Fehling's solution could be obtained. It is interesting to note that, in these same rabbits, there was no definite hypoglycemia after Rabbit XXIII had received 0.81 tuberculin in the course of three months, and after Rabbit XXXV had received 3.1 tuberculin in the course of one month and a half. In another rabbit, No. XXV, after $4.31 \mathrm{gm}$. tuberculin had been given in the course of four months, an infinitesimal amount of glucose- 0.006 per cent.-was found. This rabbit after receiving $0.87 \mathrm{gm}$. of tuberculin in the course of two months, showed a blood sugar content which equaled about 50 per cent. of the normal. Rabbit XXXIV, after $7.7 \mathrm{gm}$. of tuberculin in the course of three months showed less than half of its normal percentage of glucose. It would seem that the total length of treatment was a more important factor in determining the decrease in the blood sugar content than the total amount of tuberculin injected. The accompanying table shows clearly the effect of tuberculin on the per cent. of glucose in the blood.

In the next place we employed a method described by Cooke ${ }^{8}$ to find whether we had interfered with the pressor function of the adrenal glands in our experimental animals. Cooke wished to compare the pressor effect of the adrenals of a person dying of tuberculosis of the

7. The method used for determining the percentage of glucose in the blood was as follows: After fasting twenty-four hours, the rabbit was etherized, the carotid artery dissected free and bled into a 50 c.c. volumetric flask containing 5 c.c. of a 2 per cent. ammonium oxalate solution, until the flask was about three-fourths full. Distilled water was then run into the flask from a buret up to the 50 c.c: mark; the amount of water used, noted, and this plus 5 subtracted from 50 to determine the amount of blood obtained. To 200 c.c. of a 2 per cent. solution of $\mathrm{HCl}$ and 200 c.c. of a 5 per cent. solution of $\mathrm{HgCl}_{2}$, contained in a 500 c.c. graduate, the contents of the flask, and enough water to make 500 c.c. were added and the whole filtered. $\mathrm{H}_{2} \mathrm{~S}$ was passed through the filtrate until a black precipitate was obtained and this was then filtered and the amount of filtrate noted. From this the proportion of the original 500 c.c. remaining as filtrate, and so the proportion of the blood it contained, was calculated. The filtrate was neutralized with $\mathrm{NaOH}$ and evaporated to about 25 c.c. Fehling's solution was added in excess. The resulting precipitate was collected on an ash-free filter paper, washed until no reaction for sulphates was obtained, dried, ignited in a weighed porcelain crucible and weighed. This gives the weight of the $\mathrm{CuO}$ thrown down by the glucose. From this the amount of glucose in the original volume of blood, and so the percentage, is calculated.

8. Cooke, J. V.: Some Observations on the Blood-Pressure-Raising Substance of the Adrenals in Acute Adrenal Insufficiency. The Archives Int. Med., 1912, ix, 108 . 
alrenals, with that found in human beings dying of some other disease. He found that the diseased portions of the tuberculous adrenals caused no rise in the hlood-pressure tracing of a dog, whereas, the extract of the "normal" adrenals caused a rise quite similar to that produced by injection of adrenalin. A "normal" rabbit was etherized, the carotid artery exposed and connected with a writing lever through a mercury manometer. The rabbit's normal pressure was written on a kymograph. One of the "treated" animals was killed, the adrenal glands removed, wround in a mortar with sand and ten rolumes of salt solution arlded, and centrifugalized. A protion of the supernatant fluid was injected into the ear vein of the "normal" rabbit. It will be seen (Figures 1 and 2), that a sharp, marked risc occurred rery quickly. We must conchade from these tracings that the pressor function of the adrenal secretion harl either been interfered with very slightly or not at all.

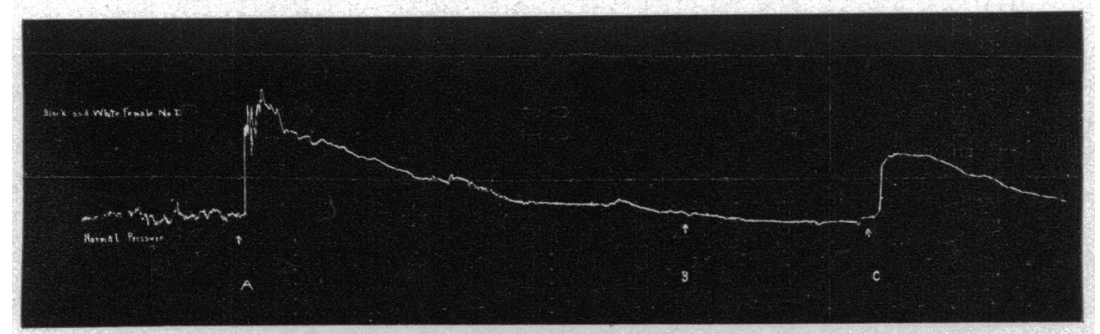

Fig. 1.-Fffect on blood-pressure of experimental injection of extract of adrenal olatul in a rabbit: A. Intravenous injection of $2 \mathrm{c.cm}$. of the extract of the adrenal glands of Rabbit No. XXXV. J3. Intravenous injection of 2 e.cm. of normal salt alution. C. Intravenous injection of 1 minim of adrenalin (P. D. \& Co.). The majked pressor effect of the adrenal extract is ayparent. This animal's blood contained so little glucose that no precipitate with Fehling's solution conld be obtained.

If we now try to interpret our findings, we would say that the marked hypoglycemia produced would strongly suggest that an extreme degree of functional insufficiency of the adrenal secretion had been bronght about. On the other liand, such a conclusion is not warranted, in the face of the fact that the pressor function remains intact and that none of the Addisonian symptoms were noted. Most of the data at our disposal lead us to believe that the glycogenic and pressor functions go land in hand-that no marked alteration occurs in the one without affecting the other. In Addison's disease we find not only a hippoglycemia but also a low blood-pressure. After injection of adrenalin we get not only a lyperglycemia but also an increased blood-pressure.

The eridence which might be presented to show that changes can oceur in the glycogenic function without involving the pressor function 





an!l vice rersa, is not of a very convincing nature. Shur and Weisel," Goldzieher and Molnár, ${ }^{10}$ and Goldzieher ${ }^{11}$ have tried to prove that the blood of chronic nephritics contains an excess of adrenalin; and the have attributed the high blood-pressure found in this disease to the action of this excess. Tf this were a fact we should have an example of a pressor effect without a corresponding glycogenic one. But O'Connor, ${ }^{12}$ Bröking and Trendelenburg, ${ }^{13}$ and Falta and Flemming ${ }^{14}$ have shown that the methods used for determining the amount of adrenal secretion present in the blood serum, are faulty; and that, consequently, the conclusions based on these methods are not tenable. Falta ${ }^{15}$ has suggested that human diabetes mellitus might, in certain instances, be the result of overfunction of the adrenal glands. If such were the case this would serve as an example of a glycogenic effect without a corresponding pressor effect. But we have no direct evidence in support of Falta's hypothesis.

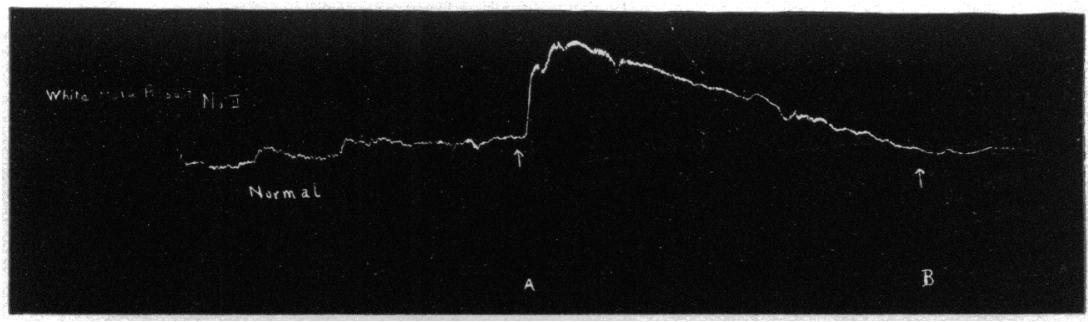

Fig. 2.-Effect on blood-pressure of experimental injection of extract of adrenal gland in a rabbit: A. Intravenous injection of $0.8 \mathrm{c.cm}$. of the extract of the adrenal glands of Rabbit No. XXXIV. B. Intravenous injection of 1.6 c.cm. of normal salt solution. The marked pressor effect of the adrenal extract is apparent. This animal's blood showed a more than 50 per cent. reduction in the glucose content.

9. Schur. H., and Weisel, I.: Beiträge zur Physiologie und Pathologie des chromatfinen Gewebes. Wien klin. Wehnschr., 1907, xx, 1202.

10. Goldzieher, M., and Molnár, B.: Beiträge zur Frage der Adrenalinamie, Wien. klin. Welınschr., 1908, xxi, 215.

11. Goldzieher, M.: Beiträge zur Pathologie der Nebennieren. Wien. klin. Wehnschr., 1910, xxiii, 809.

12. O'Connor, J. M.: Ceber Adrenalinbestimmung im Blute. Minchen. med. Wehnschr., 1911, lviii, 1439.

13. Bröking, E., and Trendelenburg. P.: Adrenalinnachweis, und Adrenalingehalt des menschlichen Blutes. Deutsch. Arch. f. klin. Med., 1911, ciii, 168.

14. Falta, W., and Flemming. G. B.: Ceber die Wirkung des Adrenalins und Pituittins auf den ïberlebenden Kaninchenuterus und über die Verwertbarkeit der Uterusmethode für den Adrenalinnachweis im Serum. München. med. Wchnschr., 1911, Iviii, 2649.

15. Falta, W.: Ceber die Gesetze der Zuckerausscheidung beim Diabetes mellitus. Ztschr. f. klin. Med., Berl., 1908, lxv, 300.

16. Fischer, Martin H.: Personal communication. 
Martin H. Fischer ${ }^{16}$ has suggested that our findings might be explained on the basis of fever produced by the tuberculo-toxin which so increased the carbohydrate metabolism of the rabbit that there was produced within the organism a great reduction of the glycogen content. This explanation might be possible but it seems to us that such marked reduction in the amount of glycogen as would be required to produce such results as were obtained in Rabbits XXIII, XXV and XXXV must necessarily be accompaned by some of the symptoms of infection such as loss of appetite, loss of weight, languor and weakness; none of which occurred as may be seen by consulting the table. Rabbit XXXV lost 0.1 kilos but this is explained by the fact that it was weighed for the first time very near the end of pregnancy. Rabbits XXIII and XXXIV maintained a constant weight and Rabbit XXV gained 0.3 kilos. At no time during the course of our experiments did any of these rabbits show any sign or symptom of disease.

It is impossible in the present state of our knowledge to give a satisfartory explanation for the results we have obtained.

\section{PROTOCOLS}

Protocol 23.-Belgian hare. Male, 1.9 kilos. From June 11, 1911. to July 9. 1911 , fifteen subcutaneous injections of tuberculin, $0.01 \mathrm{gm}$. at each injection.

From July II, 1911, to July 27, 1911, nine injections of tuberculin. $0.02 \mathrm{gm}$. at each injection.

From July 28, 1911, to Alugnst 29, 1911, twelve injections of tuberculin. 0.06 gm. at each injection.

From August 30, 1911. to the end of the experiment November 5, 1911, thirtyfive injections of tuberculin, $0.10 \mathrm{gm}$. at each injection.

August 13, 1911, blood from right carotid artery showed 0.130 per cent. glucose.

October 22, 1911. blood from left carotid artery showed no precipitate with fehling's solution.

Protocol 24.-Black and white rabbit. Male, 2.6 kilos.

June 14, 1911, blood from right carotid artery showed 0.1 õ per cent glucose. No further observation.

PкотосоL 25.-White rabbit. Male, 1.9 kilos.

From June 23, 1911, to July 9, 1911, nine injections of tubereulin, $0.01 \mathrm{gm}$. at each injection.

From July 11, 1911, to July 27, 1911, nine injections of tuberculin. $0.02 \mathrm{gm}$. at each injection.

From July 30, 1911, to August 29. 1911, fourteen injections of tuberculin, 0.06 gm. at each injection.

August 19, 1911, blood from right carotid artery shows 0.082 per cent. glucose.

From September 2, 1911, to November 5, 1911, thirty-nine injections of tuberculin. $0.10 \mathrm{gm}$. at each injection.

October 29, 1911, blood from left carotid artery shows 0.006 per cent. glucose.

December 10, 1911, thirty-five days after the last injections of tubereulin. blood from femoral artery shows 0.094 per cent. glucose.

Protocol 30.-White rabbit. Female, $2.0 \mathrm{kilos}$.

Blood from right carotid artery shows 0.098 per cent. glucose. No further observation.

Protocol 34.- White rabbit. Male, 2.7 kilos.

December 23,1911 , blood from right earotid artery shows 0.133 per cent. glucose. 
December 28, 1911, to April 14, 1912, ninety injections of tuberculin, $0.10 \mathrm{gm}$. at each injection.

April 1, 1912, blood from left carotid artery shows 0.061 per cent. glucose.

April 15, 1912, animal killed by a blow on the head. Adrenal glands removed and macerated in salt solution; 2 c.c. injected into the ear vein of a normal rabbit writing blood-pressure as shown in Fig. 2.

Protocol 35.-Black and white rabbit. Female, 2.0 kilos. January 8, 1912, to April 6, 1912, seventy-five injections of tuberculin, $0.10 \mathrm{gm}$. at each injection. January 24, 1912, a litter of four born dead.

February 16, 1912, blood from right carotid artery shows a definite glycemia. Precipitate lost.

April 2, 1912, blood from left carotid artery shows no precipitate with Fehling's solution.

April 7,1912 , animal killed by a blow on the head. Adrenal glands removed and macerated in salt solution. Two c.c. injected into the ear vein of a normal rabbit writing blood-pressure as shown in Fig. 1.

4li Marlborough Street-Cniversity of Cincinnati. 